Int. J. Electrochem. Sci., 12 (2017) 3931 - 3940

\title{
Fabrication of highly sensitive nitrite electrochemical sensor in foodstuff using nanostructure sensor
}

\author{
Vinod Kumar Gupta ${ }^{1, *}$, Mohammad A. Khalilzadeh, ${ }^{2, *}$, Ali Rudbaraki ${ }^{3}$, Shilpi Agarwal, \\ Mehmet L. Yola ${ }^{4}$ Necip Atar ${ }^{5}$ \\ ${ }^{1}$ Department of Applied Chemistry, University of Johannesburg, Johannesburg, South Africa \\ ${ }^{2}$ Department of Chemistry, Qaemshahr Branch, Islamic Azad University, Qaemshahr, Iran \\ ${ }^{3}$ Department of Food Science, Sari Branch, Islamic Azad University, Sari, Iran \\ ${ }^{4}$ Department of Metallurgical and Materials Engineering, Faculty of Engineering, Sinop University, \\ Sinop, Turkey \\ ${ }^{5}$ Department of Chemical Engineering, Pamukkale University, Denizli, Turkey \\ *E-mail: vinodfcy@gmail.com, khalilzadeh73@gmail.com
}

doi: $10.20964 / 2017.05 .72$

Received: 23 February 2017 / Accepted: 14 March 2017 / Published: 12 April 2017

In this research, we introduced a powerful electrochemical sensor (based carbon paste electrode) for analysis of nitrite in foodstuff, using $\mathrm{CdO}$ decorated single wall carbon nanotube incorporated with 1methyl-3-butylimidazolium bromide (CdO/SWCNTs/1-3-MBIB/CPE). Our results revealed that $\mathrm{CdO} / \mathrm{SWCNTs} / 1-3-\mathrm{MBIB} / \mathrm{CPE}$ shows excellent electro-catalytic activity towards electro-oxidation of nitrite. The obtained data illustrated an irreversible oxidation peak current at $0.92 \mathrm{~V}$, pointing to the oxidation of nitrite. The $\mathrm{CdO} / \mathrm{SWCNT} / 1-3-\mathrm{MBIB} / \mathrm{CPE}$ exhibited a linear response from $0.1 \mu \mathrm{M}$ to $900.0 \mu \mathrm{M}$ of nitrite with no interfering from other food compounds. The $\mathrm{CdO} / \mathrm{SWCNTs} / 1-3-$ $\mathrm{MBIB} / \mathrm{CPE}$ has been used for determination of nitrite in real samples.

Keywords: Nitrite determination, CdO/SWCNTs, Sensor, Food analysis

\section{FULL TEXT}

(C) 2017 The Authors. Published by ESG (www.electrochemsci.org). This article is an open access article distributed under the terms and conditions of the Creative Commons Attribution license (http://creativecommons.org/licenses/by/4.0/). 